ARTICLE

\title{
A reasonable approach for the generation of hollow icosahedral kernels in metal nanoclusters
}

\author{
Xi Kang ${ }^{1,2,4}$, Xiao Wei ${ }^{1,2,4}$, Xiaokang Liu $^{3}$, Sicong Wang ${ }^{3}$, Tao Yao $\mathbb{1}^{3 凶}$, Shuxin Wang $\mathbb{D}^{1,2 \bowtie} \&$
} Manzhou Zhu (D) $1,2 \bowtie$

Although the hollow icosahedral $M_{12}$ kernel has been extensively observed in metal nanoclusters, its origin remains a mystery. Here we report a reasonable avenue for the generation of the hollow icosahedron: the kernel collapse from several small nano-building blocks to an integrated hollow icosahedron. On the basis of the Au alloying processes from $\mathrm{Ag}_{28} \mathrm{Cu}_{12}(\mathrm{SR})_{24}$ to the template-maintained $\mathrm{Au}_{x} \mathrm{Ag}_{28-\mathrm{x}} \mathrm{Cu}_{12}(\mathrm{SR})_{24}$ and then to the templatetransformed $\mathrm{Au}_{12} \mathrm{Cu}_{\mathrm{y}} \mathrm{Ag}_{32-\mathrm{y}}(\mathrm{SR})_{30}$, the kernel evolution/collapse from "tetrahedral $\mathrm{Ag}_{4}+$ $4 * \mathrm{Ag}_{3}$ " to "tetrahedral $\mathrm{Au}_{4}+4 * \mathrm{M}_{3}(\mathrm{M}=\mathrm{Au} / \mathrm{Ag})$ " and then to "hollow icosahedral $\mathrm{Au}_{12}$ " is mapped out. Significantly, the "kernel collapse" from small-sized nano-building blocks to large-sized nanostructures not only unveils the formation of hollow icosahedral $M_{12}$ in this work, but also might be a very common approach in constructing metallic kernels of nanoclusters and nanoparticles (not limited to the $M_{12}$ structure).

\footnotetext{
${ }^{1}$ Department of Chemistry and Centre for Atomic Engineering of Advanced Materials, Anhui Province Key Laboratory of Chemistry for Inorganic/Organic Hybrid Functionalized Materials, Anhui University, Hefei, Anhui, People's Republic of China. ${ }^{2}$ Key Laboratory of Structure and Functional Regulation of Hybrid Materials, Anhui University, Hefei, Anhui, People's Republic of China. ${ }^{3}$ National Synchrotron Radiation Laboratory, University of Science and Technology of China, Hefei, Anhui, People's Republic of China. ${ }^{4}$ These authors contributed equally: Xi Kang, Xiao Wei. ${ }^{凶}$ email: yaot@ustc.edu.cn;

shuxin_wang@qust.edu.cn; zmz@ahu.edu.cn
} 
$\mathrm{M}$ etal nanoclusters are an emerging class of modular nanomaterials ${ }^{1-6}$, and have been sparking great research interests owing to their atomically precise structures and intriguing properties ${ }^{7-27}$. The physiochemical properties of these nanomaterials, such as chirality, luminescence, catalysis, magnetism, and electrochemistry, can be rationalized in terms of their quantum size effect as well as discrete electronic states $^{28-38}$. Besides, the atomically precise nature of these modular nanomaterials is of the most interest - indeed, compared with large-sized nanoparticles, nanoclusters (typically $<2 \mathrm{~nm}$ of the metallic kernel) present more precise compositions/constructions, and thus allow for the atomic-level elucidation of structural evolutions and structure-property correlations ${ }^{1-6,39-46}$.

Of all reported nanoclusters with precise structures, the icosahedral configuration is the most typical, which is frequently observed in both metal kernels and ligand shells of nanoclusters ${ }^{4-51}$. Interestingly, except for the non-hollow icosahedral $M_{1} @ M_{12}$ kernel ( $M$ represents the metal), the hollow icosahedral $\mathrm{M}_{12}$ kernel has also served as a basic nano-building block of nanoclusters (e.g., $\mathrm{Ag}_{44}(\mathrm{SR})_{30}, \mathrm{Au}_{12+n} \mathrm{Cu}_{32}(\mathrm{SR})_{30+n}$, $\mathrm{Ag}_{50}(\mathrm{dppm})_{6}(\mathrm{SR})_{30}, \mathrm{Au}_{144}(\mathrm{SR})_{60}$, etc. $)^{10,11,52-56}$. Structurally, it is accepted that the non-hollow icosahedron might be more energetically favorable than the corresponding hollow one due to the extra 12 metal...metal interactions in $\mathrm{M}_{1} @ \mathrm{M}_{12}$; accordingly, the hollow icosahedral kernel is unlikely to arise in the initial stage of the nanocluster growth. Besides, the hollow $\mathrm{M}_{12}$ kernel is also less likely to originate from its non-hollow counterpart because the 12 metal $\cdots$ metal interactions make it difficult to extract the innermost metal atom out. In this context, the origin of such hollow icosahedral kernels remains a mystery.

In this work, based on the Au-alloying-induced nanocluster transformation from $\mathrm{M}_{40}(\mathrm{SR})_{24}$ to $\mathrm{M}_{44}(\mathrm{SR})_{30}(\mathrm{M}=\mathrm{Au} / \mathrm{Ag} / \mathrm{Cu})$, a reasonable avenue for the generation of hollow icosahedral $M_{12}$ kernels has been mapped out, i.e., the kernel collapse from several small nano-building blocks to an integrated hollow icosahedron. The proposed avenue might serve as a common approach in constructing metallic kernels of nanoclusters and nanoparticles (not limited to the $\mathrm{M}_{12}$ structure).

\section{Results}

Structural anatomy of $\mathrm{M}_{40}(\mathrm{SR})_{24}$ and $\mathrm{M}_{44}(\mathrm{SR})_{30}$ nanoclusters. For the clarity of the structural transformation and the corresponding kernel collapse, the nanocluster structures involved in this work are first discussed (Fig. 1) -

(i) $\mathrm{M}_{40}(\mathrm{SR})_{24} \quad\left(\mathrm{M}=\mathrm{Au} / \mathrm{Ag} / \mathrm{Cu} ; \mathrm{SR}=\mathrm{SPhCl}_{2}\right)$ : the $\mathrm{M}_{40}(\mathrm{SR})_{24}$ nanoclusters start from the bi-metallic $\mathrm{Ag}_{28} \mathrm{Cu}_{12}(\mathrm{SR})_{24}{ }^{57}$. Figure 1a-d depict the structure anatomy of $\mathrm{Ag}_{28} \mathrm{Cu}_{12}(\mathrm{SR})_{24}$. $\mathrm{Ag}_{28} \mathrm{Cu}_{12}(\mathrm{SR})_{24}$ adopts a three-shell configuration, in a form of $\mathrm{Ag}_{4}\left(\mathrm{M}_{40}-\mathrm{S} 1\right) @ \mathrm{Ag}_{24}\left(\mathrm{M}_{40}-\mathrm{S} 2\right) @ 4^{*} \mathrm{Cu}_{3}(\mathrm{SR})_{6}\left(\mathrm{M}_{40}-\mathrm{S} 3\right)$. The innermost $\mathrm{Ag}_{4}$ is in tetrahedral (Fig. 1a). The $24 \mathrm{Ag}$ atoms on $\mathrm{M}_{40^{-}}$ $\mathrm{S} 2 \mathrm{can}$ be divided into two categories, and each of $12 \mathrm{Ag}$ atoms constitute four $\mathrm{Ag}_{3}$ triangles (Fig. 1b). The $\mathrm{Ag}$ atoms highlighted in dark blue connect with inward SR ligands on $\mathrm{M}_{40} \mathrm{~S} 3$ (Fig. 1c, highlighted in yellow); in contrast, the $\mathrm{Ag}$ atoms in light blue links outward SR ligands (highlighted in red) on $\mathrm{M}_{40}-\mathrm{S} 3$.

(ii) $\mathrm{M}_{44}(\mathrm{SR})_{30}\left(\mathrm{M}=\mathrm{Au} / \mathrm{Ag} / \mathrm{Cu} ; \mathrm{SR}=\mathrm{SPhCl}_{2}\right)$ : the $\mathrm{Au}_{12} \mathrm{Ag}_{32}(\mathrm{SR})_{30}$ nanocluster is adopted to analyze the structure of $\mathrm{M}_{44}(\mathrm{SR})_{30}{ }^{58}$. $\mathrm{Au}_{12} \mathrm{Ag}_{32}(\mathrm{SR})_{30}$ also has a three-shell configuration: $\mathrm{Au}_{12}\left(\mathrm{M}_{44^{-}}\right.$ $\mathrm{S} 1) @ \mathrm{Ag}_{20}\left(\mathrm{M}_{44}-\mathrm{S} 2\right) @ 6^{*} \mathrm{Ag}_{2}(\mathrm{SR})_{5}\left(\mathrm{M}_{44}-\mathrm{S} 3\right)$. Of note, the $\mathrm{Au}_{12}$ kernel is a hollow icosahedron (Fig. 1e).

Au-alloying-induced transformation from $\mathrm{M}_{40}(\mathrm{SR})_{24}$ to $\mathbf{M}_{44}(\mathrm{SR})_{30}$. The Au-alloying structural transformation started from the bi-metallic $\mathrm{Ag}_{28} \mathrm{Cu}_{12}(\mathrm{SR})_{24}$ (Fig. 2). The slight $\mathrm{Au}$ alloying on $\mathrm{Ag}_{28} \mathrm{Cu}_{12}(\mathrm{SR})_{24}$ resulted in a tri-metallic $\mathrm{Au}_{x} \mathrm{Ag}_{28-x} \mathrm{Cu}_{12}(\mathrm{SR})_{24}$ $(x=1.32)$ nanocluster, wherein the tetrahedral $\mathrm{Ag}_{4}$ kernel of $\mathrm{Ag}_{28} \mathrm{Cu}_{12}(\mathrm{SR})_{24}$ was partially alloyed by the incorporated $\mathrm{Au}$ (Fig. 2 and Supplementary Fig. 1). When more Au heteroatoms were doped into $\mathrm{M}_{40}(\mathrm{SR})_{24}\left(\mathrm{Au}_{x} \mathrm{Ag}_{28-x} \mathrm{Cu}_{12}(\mathrm{SR})_{24}, x=7.56\right.$; Fig. 2), all sites of the tetrahedron were entirely occupied by Au; besides, the redundant Au heteroatoms were further arranged onto $\mathrm{M}_{40}-\mathrm{S} 2$, invading the $\mathrm{Ag}$ sites that related to outward SR thiols (light blue triangles in Fig. $1 \mathrm{~b}$ and Supplementary Figs. 2-3). Of note, throughout the abovementioned Au-alloying processes the $\mathrm{M}_{40}(\mathrm{SR})_{24}$ framework retained. Furthermore, the overdose of Au heteroatom induced the structural transformation from $\mathrm{M}_{40}(\mathrm{SR})_{24}$ to $\mathrm{M}_{44}(\mathrm{SR})_{30}$. Structurally, from the crystal structure of $\mathrm{Au}_{12} \mathrm{Cu}_{y} \mathrm{Ag}_{32-y}(\mathrm{SR})_{30}$ ( $y=0-6$; Avg. 3.74; Fig. 2 and Supplementary Fig. 4), the $\mathrm{M}_{44}(\mathrm{SR})_{30}$ nanocluster reached its stable state when $\mathrm{Cu}$ atoms only occupied the $\mathrm{M}_{44}-\mathrm{S} 3$. The corresponding bond lengths in $\mathrm{M}_{40}(\mathrm{SR})_{24}$ (including $\mathrm{Ag}_{28} \mathrm{Cu}_{12}(\mathrm{SR})_{24}$, $\mathrm{Au}_{x} \mathrm{Ag}_{28-x} \mathrm{Cu}_{12}(\mathrm{SR})_{24} \quad(x=1.32), \mathrm{Au}_{x} \mathrm{Ag}_{28-x} \mathrm{Cu}_{12}(\mathrm{SR})_{24} \quad(x=7.56)$, and $\left.\mathrm{Au}_{4} \mathrm{Ag}_{24} \mathrm{Cu}_{12}(\mathrm{SR})_{24}\right)$ or $\mathrm{M}_{44}(\mathrm{SR})_{30}$ (including $\mathrm{Au}_{12} \mathrm{Ag}_{32}(\mathrm{SR})_{30}$ and $\left.\mathrm{Au}_{12} \mathrm{Cu}_{y} \mathrm{Ag}_{32-y}(\mathrm{SR})_{30}, y=3.74\right)$ nanoclusters were compared in detail (Supplementary Figs. 5-6 and Supplementary Tables 1-2).

Despite our repeated best efforts to obtain the crystal structure of $\mathrm{Au}_{12} \mathrm{Cu}_{y} \mathrm{Ag}_{32-y}(\mathrm{SR})_{30}$, its perfect crystal data remains unavailable. Herein, for acquiring an excellent crystal data of $\mathrm{Au}_{12} \mathrm{Cu}_{y} \mathrm{Ag}_{32-y}(\mathrm{SR})_{30}$, we promoted the co-crystallization between the $\mathrm{M}_{44}(\mathrm{SR})_{30}$ and a small-sized $\mathrm{M}_{40}(\mathrm{SR})_{24}$ nanoclusters (Supplementary Figs. 7-9). Fortunately, the structures of both two nanoclusters were excellently determined $\left(\mathrm{Au}_{4} \mathrm{Ag}_{24} \mathrm{Cu}_{12}(\mathrm{SR})_{24}\right.$ and $\left.\mathrm{Au}_{12} \mathrm{Cu}_{y} \mathrm{Ag}_{32-y}(\mathrm{SR})_{30}(y=3.74)\right)$ although both displayed strongly negative valence state (i.e., "- 4 "). In this context, the presence of $\left(\mathrm{PPh}_{4}\right)^{+}$cations neutralized the electrostatic repulsion between these clusters (Supplementary Fig. 8) and thus promoted the nanocluster co-crystallization, which was different from previously reported co-crystallized nanocluster cases with both "0" or opposite valence states ${ }^{59-62}$. In the crystal lattice of the cocrystallized nanoclusters, three types of nanoclusters were observed (Supplementary Fig. 7) $-L-\mathrm{Au}_{4} \mathrm{Ag}_{24} \mathrm{Cu}_{12}(\mathrm{SR})_{24}(\mathrm{~A} \alpha$, $\mathrm{A} \beta), \quad R-\mathrm{Au}_{4} \mathrm{Ag}_{24} \mathrm{Cu}_{12}(\mathrm{SR})_{24}(\mathrm{~B} \alpha, \mathrm{B} \beta)$, and $\mathrm{Au}_{12} \mathrm{Cu}_{y} \mathrm{Ag}_{32-y}(\mathrm{SR})_{30}$ $(y=3.74 ; \mathrm{C} \alpha, \mathrm{C} \beta)$, among which the $\alpha$ - and $\beta$-nanoclusters were identical, but arranged in different rotation angles (Supplementary Fig. $7 \mathrm{a}-\mathrm{c}$ ). In contrast to the crystallization of homogeneous nanoclusters, which are typically packed into superlattices with simple translational symmetry, such as $A B A B$ or $A B C A B C$ packing pattern ${ }^{40}$, the $(\mathrm{AuAgCu})_{40}$ and $(\mathrm{AuAgCu})_{44}$ nanoclusters were packed with a more complex pattern (Supplementary Fig. $7 \mathrm{~d}-\mathrm{f}$ ). From the $x$-axis view, the clusters were packed with an $\mathrm{A} \alpha-\mathrm{B} \alpha-\mathrm{C} \alpha \# \mathrm{~A} \beta-\mathrm{B} \beta-\mathrm{C} \beta$ pattern. $\alpha$ - and $\beta$-nanoclusters were arranged separately along the $z$-direction, giving rise to $\alpha$ - and $\beta$ cluster lines (Supplementary Fig. 7f). In either cluster line, the adjacent three nanoclusters constituted a repetitive unit, $A \alpha-B \alpha$ $\mathrm{C} \alpha$ or $\mathrm{A} \beta-\mathrm{B} \beta-\mathrm{C} \beta$, which was labeled by red or black frames, respectively. Such repetitive units were also observed from $y$-axis and $z$-axis views (Supplementary Fig. 7).

The optical absorptions of the obtained nanocluster crystals (dissolved in $\mathrm{CH}_{2} \mathrm{Cl}_{2}$ ) were compared (Supplementary Fig. 10). Along with the Au-alloying process from $\mathrm{Ag}_{28} \mathrm{Cu}_{12}(\mathrm{SR})_{24}$ to $\mathrm{Au}_{x} \mathrm{Ag}_{28-x} \mathrm{Cu}_{12}(\mathrm{SR})_{24} \quad(x=1.32) \quad$ and $\quad \mathrm{Au}_{x} \mathrm{Ag}_{28-x} \mathrm{Cu}_{12}(\mathrm{SR})_{24}$ $(x=7.56)$, there was no significant alteration of the optical absorptions $(405,465$, and $555 \mathrm{~nm})$. By contrast, when the nanocluster template transformed from $\mathrm{M}_{40}(\mathrm{SR})_{24}$ to $\mathrm{M}_{44}(\mathrm{SR})_{30}$, these absorptions shifted to 390,490 , and $595 \mathrm{~nm}$ immediately (Supplementary Fig. 10), demonstrating the remarkable change over electronic structures with the template transformation. Time-dependent UV-vis of the transformation from $\mathrm{Ag}_{28} \mathrm{Cu}_{12}(\mathrm{SR})_{24}$ to $\mathrm{Au}_{x} \mathrm{Ag}_{28-x} \mathrm{Cu}_{12}(\mathrm{SR})_{24}$ and then to $\mathrm{Au}_{12} \mathrm{Cu}_{y} \mathrm{Ag}_{32-y}(\mathrm{SR})_{30}$ were performed to track the cluster 
$\mathrm{M}_{40}(\mathrm{SR})_{24}$ [Crystal Structure of $\mathrm{Ag}_{28} \mathrm{Cu}_{12}(\mathrm{SR})_{24}$ ]

a

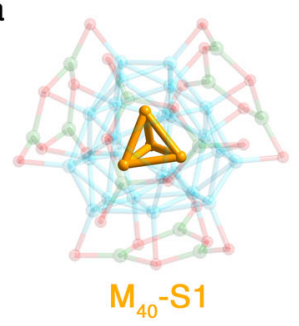

b

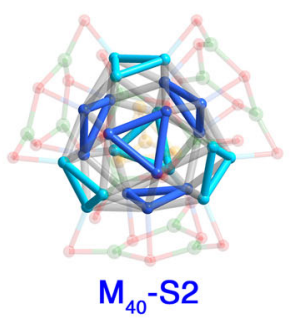

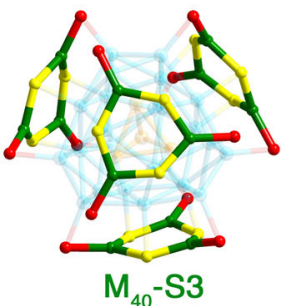

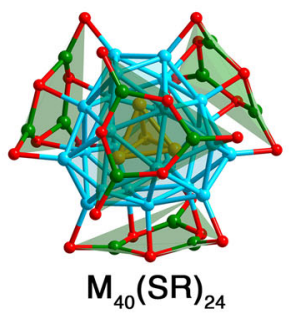

$\mathrm{M}_{44}(\mathrm{SR})_{30}$ [Crystal Structure of $\mathrm{Au}_{12} \mathrm{Ag}_{32}(\mathrm{SR})_{30}$ ]

e

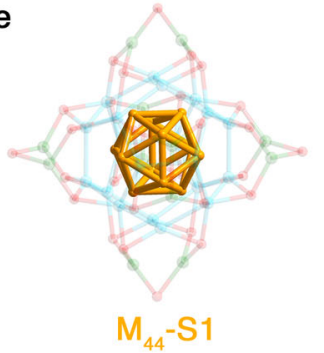

f

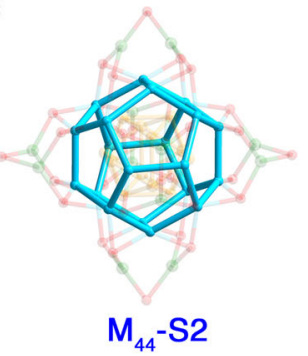

g

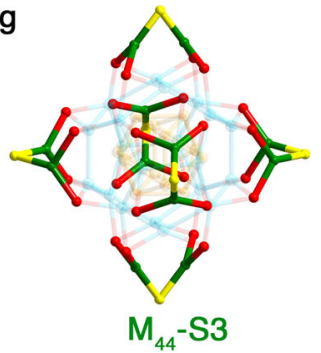

$\mathrm{h}$

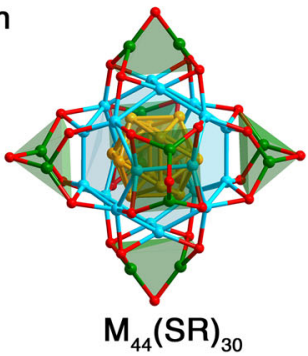

Fig. 1 Structure anatomies of $\mathbf{M}_{\mathbf{4 0}}\left(\mathrm{SPhCl}_{\mathbf{2}}\right)_{\mathbf{2 4}}$ and $\mathbf{M}_{\mathbf{4 4}}\left(\mathrm{SPhCl}_{\mathbf{2}}\right)_{\mathbf{3 0}}(\mathbf{M}=\mathbf{A u} / \mathbf{A g} / \mathbf{C u})$. a-d Structure anatomy of $\mathrm{M}_{40}\left(\mathrm{SPhCl}_{2}\right)_{24}:$ a $\mathrm{M}_{40}-\mathrm{Sl}$ : the tetrahedral $\mathrm{M}_{4}$ kernel; $\mathbf{b} \mathrm{M}_{40}-\mathrm{S} 2$ : the $\mathrm{M}_{24}$ shell; $\mathbf{c} \mathrm{M}_{40}$-S3: the $\mathrm{Cu}_{12}(\mathrm{SR})_{24}$ surface; and $\mathbf{d}$ The overall structure of $\mathrm{M}_{40}\left(\mathrm{SPhCl}_{2}\right)_{24}$ - e-h Structure anatomy of $\mathrm{M}_{44}\left(\mathrm{SPhCl}_{2}\right)_{30}$. e $\mathrm{M}_{44}-\mathrm{S} 1$ : the hollow icosahedral $\mathrm{M}_{12}$ kernel; $\mathbf{f} \mathrm{M}_{44}-\mathrm{S} 2$ : the $\mathrm{M}_{20}$ shell; $\mathbf{g} \mathrm{M}_{40}-\mathrm{S} 3$ : the $\mathrm{M}_{12}(\mathrm{SR})_{30}$ surface; and $\mathbf{h}$ The overall structure of $\mathrm{M}_{44}\left(\mathrm{SPhCl}_{2}\right)_{30}$. Color labels: orange/light blue/blue/green, $\mathrm{Ag}$ or $\mathrm{Cu}$ atoms at different positions; red, $\mathrm{S}$. All $\mathrm{C}$ and $\mathrm{H}$ atoms are omitted for clarity.

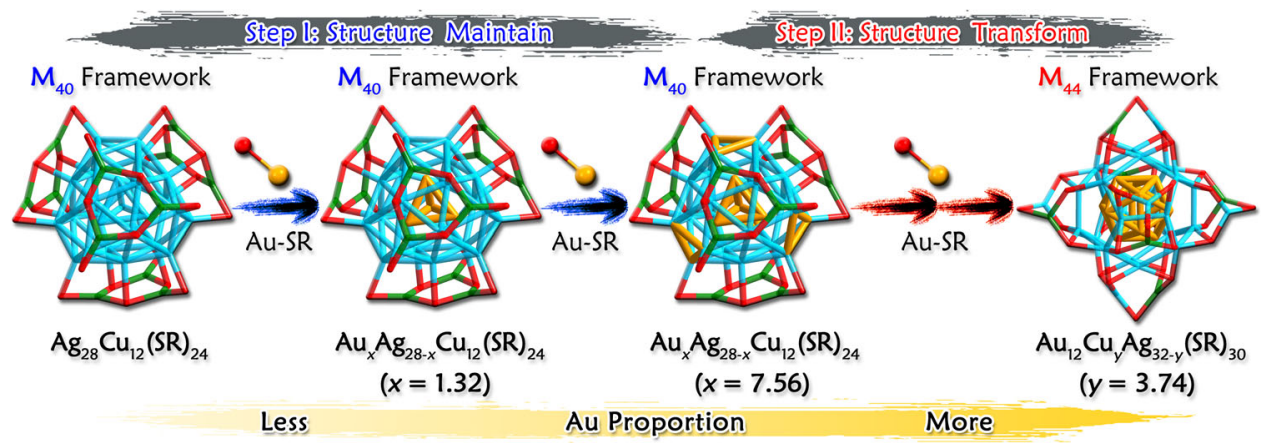

Fig. 2 Illustration of Au-alloying-induced structural evolution. Step I contains the Au-doping processes from $\mathrm{Ag}_{28} \mathrm{Cu}_{12}\left(\mathrm{SR}_{24}\right.$ to $\mathrm{Au}_{x} \mathrm{Ag}_{28-x} \mathrm{Cu}_{12}(\mathrm{SR})_{24}$ $(x=1.32)$ and then to $\mathrm{Au}_{x} \mathrm{Ag}_{28-x} \mathrm{Cu}_{12}(\mathrm{SR})_{24}(x=7.56)$, in which processes the $\mathrm{M}_{40}(\mathrm{SR})_{24}$ framework retains. Step II is the $A u$-doping process from $A u_{x} A g_{28}$ ${ }_{x} \mathrm{Cu}_{12}(\mathrm{SR})_{24}(x=7.56)$ to $\mathrm{Au}_{12} \mathrm{Cu}_{\mathrm{y}} \mathrm{Ag}_{32-y}(\mathrm{SR})_{30}(y=3.74)$, in which process the $\mathrm{M}_{40}(\mathrm{SR})_{24}$ framework transforms into $\mathrm{M}_{44}(\mathrm{SR})_{30}(\mathrm{M}=\mathrm{Au} / \mathrm{Ag} / \mathrm{Cu})$. The Au proportion gradually increases with the nanocluater evolution from $\mathrm{Ag}_{28} \mathrm{Cu}_{12}(\mathrm{SR})_{24}$ to $\mathrm{Au}_{x} \mathrm{Ag}_{28-x} \mathrm{Cu}_{12}(\mathrm{SR})_{24}(x=1.32), \mathrm{Au}_{x} \mathrm{Ag}_{28-x} \mathrm{Cu}_{12}(\mathrm{SR})_{24}(x=7.56)$, and $\mathrm{Au}_{12} \mathrm{Cu}_{y} \mathrm{Ag}_{32-y}(\mathrm{SR})_{30}(y=3.74)$. Color labels: light blue, $\mathrm{Ag}$; orange, $\mathrm{Au}$; green, $\mathrm{Cu}$; red, $\mathrm{S}$. All $\mathrm{C}$ and $\mathrm{H}$ atoms are omitted for clarity.

transformation (Supplementary Fig. 11a). The changes of UV-vis contained two stages: (stage 1, from $\mathrm{Ag}_{28} \mathrm{Cu}_{12}(\mathrm{SR})_{24}$ to $\mathrm{Au}_{x} \mathrm{Ag}_{28-}$ $\left.{ }_{x} \mathrm{Cu}_{12}(\mathrm{SR})_{24}\right)$ eight isoabsorption points at $360,385,420,445,485$, 550, 570, and $640 \mathrm{~nm}$ were observed (Supplementary Fig. 11b); (stage 2, from $\mathrm{Au}_{x} \mathrm{Ag}_{28-x} \mathrm{Cu}_{12}(\mathrm{SR})_{24}$ to $\mathrm{Au}_{12} \mathrm{Cu}_{y} \mathrm{Ag}_{32-y}(\mathrm{SR})_{30}$ ) three isoabsorption points at 400,485 , and $510 \mathrm{~nm}$ were detected (Supplementary Fig. 11c). The observation of these isoabsorption points suggested that the overall cluster transformation was a proportional conversion. Accordingly, both transformations from $\mathrm{Ag}_{28} \mathrm{Cu}_{12}(\mathrm{SR})_{24}$ to $\mathrm{Au}_{x} \mathrm{Ag}_{28-x} \mathrm{Cu}_{12}(\mathrm{SR})_{24}$ and from $\mathrm{Au}_{x} \mathrm{Ag}_{28-}$ ${ }_{x} \mathrm{Cu}_{12}(\mathrm{SR})_{24}$ to $\mathrm{Au}_{12} \mathrm{Cu}_{y} \mathrm{Ag}_{32-y}(\mathrm{SR})_{30}$ followed an "intramolecular rearrangement" approach, but not an "intermolecular decomposition-recombination" approach.

Besides, along with the Au-alloying process, the thermal stability of nanoclusters was enhanced. As shown in Supplementary Fig. 12, UV-vis characteristic absorptions of the $\mathrm{Ag}_{28} \mathrm{Cu}_{12}(\mathrm{SR})_{24}$ nanocluster (dissolved in $\mathrm{CH}_{2} \mathrm{Cl}_{2}$ ) gradually decreased in intensity after $1 \mathrm{~h}$ and completely disappeared in $\sim 4 \mathrm{~h}$, indicating degradation. In contrast, the UV-vis absorptions of $\mathrm{Au}_{x} \mathrm{Ag}_{28-x} \mathrm{Cu}_{12}(\mathrm{SR})_{24}(x=1.32)$ were essentially identical in the first $2 \mathrm{~h}$, and gradually decreased as time went on. Of note, the optical absorptions of $\mathrm{Au}_{x} \mathrm{Ag}_{28-x} \mathrm{Cu}_{12}(\mathrm{SR})_{24}$ $(x=7.56)$ was almost retained within $24 \mathrm{~h}$, suggesting the enhanced thermal stability of $\mathrm{Au}_{x} \mathrm{Ag}_{28-x} \mathrm{Cu}_{12}(\mathrm{SR})_{24} \quad(x=7.56)$ over other two $\mathrm{M}_{40}(\mathrm{SR})_{24}$ nanoclusters. In this context, the sequence of the thermal stability of these three $\mathrm{M}_{40}(\mathrm{SR})_{24}$ nanoclusters was determined as $\mathrm{Au}_{x} \mathrm{Ag}_{28-x} \mathrm{Cu}_{12}(\mathrm{SR})_{24}(x=7.56)>$ $\mathrm{Au}_{x} \mathrm{Ag}_{28-x} \mathrm{Cu}_{12}(\mathrm{SR})_{24}(x=1.32)>\mathrm{Ag}_{28} \mathrm{Cu}_{12}(\mathrm{SR})_{24}$; that is, increasing the Au-doping amount in nanoclusters was in favor of preparing $\mathrm{M}_{40}(\mathrm{SR})_{24}$ with higher thermal stability.

Electrospray ionization mass spectrometry (ESI-MS) was then performed on nanocluster crystals (dissolved in $\mathrm{CH}_{2} \mathrm{Cl}_{2}$ ), and the mass results confirmed the compositions of these " 4 "-charged $\mathrm{M}_{40}(\mathrm{SR})_{24}$ and $\mathrm{M}_{44}(\mathrm{SR})_{30}$ nanoclusters (Supplementary Fig. 13). Besides, the in-situ Au-alloying process and the nanocluster template transformation were tracked by exploiting the ESI-MS (Supplementary Figs. 14-18). At the very beginning process (1-2 min in 
Supplementary Fig. 14), only $\mathrm{Au}_{x} \mathrm{Ag}_{28-x} \mathrm{Cu}_{12}(\mathrm{SR})_{24}$ nanoclusters were detected (Fig. 2), corresponding to the Au-doping process from $\mathrm{Ag}_{28} \mathrm{Cu}_{12}(\mathrm{SR})_{24}$ to $\mathrm{Au}_{x} \mathrm{Ag}_{28-x} \mathrm{Cu}_{12}(\mathrm{SR})_{24}(x=1.32)$ and $\mathrm{Au}_{x} \mathrm{Ag}_{28-}$ ${ }_{x} \mathrm{Cu}_{12}(\mathrm{SR})_{24}(x=7.56)$. The further Au-alloying induced both the $\mathrm{Au}$ component growth in $\mathrm{M}_{40}(\mathrm{SR})_{24}$ and the template transformation from $\mathrm{M}_{40}(\mathrm{SR})_{24}$ to $\mathrm{M}_{44}(\mathrm{SR})_{30}$ (3-6 min in Supplementary Fig. 14). Finally, only $\mathrm{Au}_{12} \mathrm{Cu}_{y} \mathrm{Ag}_{32-y}(\mathrm{SR})_{30}$ nanoclusters could be observed (7-8 min in Supplementary Fig. 14), which suggested the complete transformation of nanoclusters. Of note, the $\mathrm{Au}_{12} \mathrm{Ag}_{32-y} \mathrm{Cu}_{y}(\mathrm{SR})_{30}$ would stable at $y=3$ or 4 once generated, matching with the crystal structure of $\mathrm{Au}_{12} \mathrm{Cu}_{y} \mathrm{Ag}_{32-y}(\mathrm{SR})_{30}(y=3.74)$. Energy-dispersive X-ray spectroscopy (EDS) mapping and X-ray photoelectron spectroscopy (XPS) were conducted to confirm the Au-alloying process (Supplementary Figs. 19-28).

Kernel transformation from tetrahedron to hollow icosahedron. Figure 3 depicts the kernel collapse from the "tetrahedral $\mathrm{Au}_{4}+4^{*} \mathrm{M}_{3}$ " to "hollow icosahedral $\mathrm{Au}_{12}$ " induced by the $\mathrm{Au}$ alloying. Specifically, the initial Au-doping process transported the $\mathrm{Au}$ heteroatoms to the tetrahedral kernel, converting the $\mathrm{Ag}_{4}$ kernel to the alloyed $\mathrm{Au}_{x} \mathrm{Ag}_{4-x}$ and the final $\mathrm{Au}_{4}$ (Fig. 3a). The further $\mathrm{Au}$ alloying sites on $\mathrm{M}_{40}-\mathrm{S} 2$ predominantly located at the four $\mathrm{M}_{3}$ triangles that adhered to a vertex-to-face relationship to the tetrahedral $\mathrm{Au}_{4}$ kernel (Fig. 3b and Supplementary Fig. 3c); in contrast, the other four triangles on $\mathrm{M}_{40}$-S2, following a face-to-face relationship to the $\mathrm{Au}_{4}$ tetrahedral kernel, maintained unalloyed as $\mathrm{Ag}_{3}$ (Supplementary

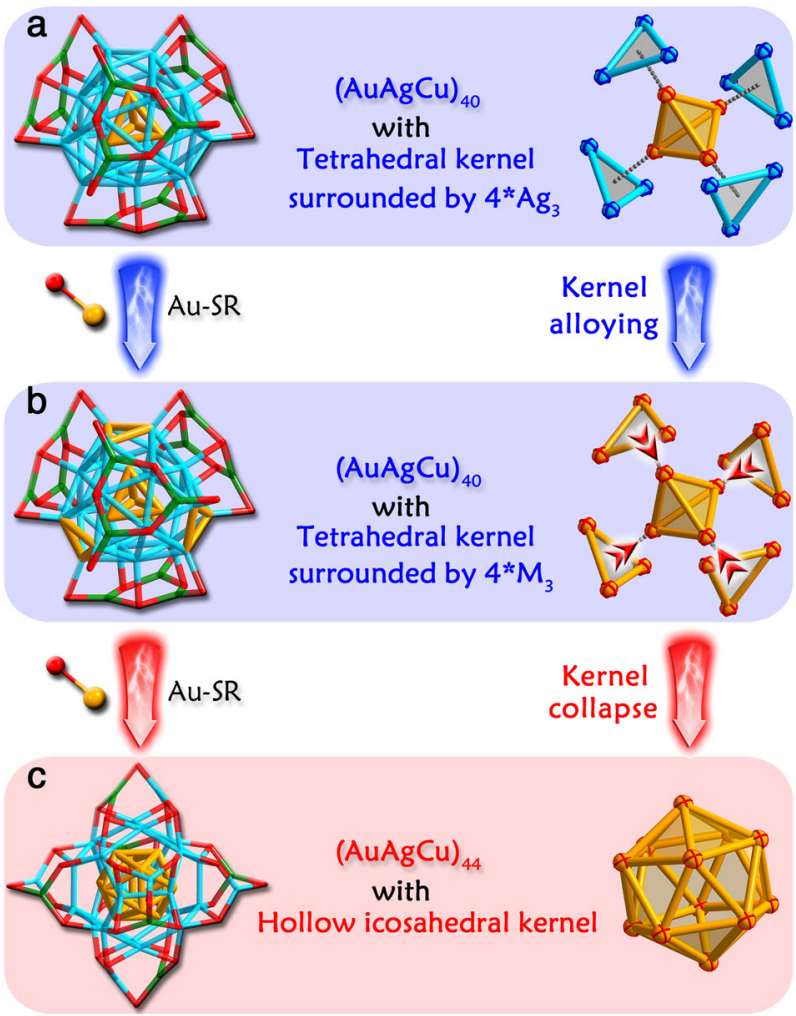

Fig. 3 Kernel transformation from tetrahedron to hollow icosahedron. a Crystal structure of $\mathrm{Au}_{x} \mathrm{Ag}_{28-x} \mathrm{Cu}_{12}(\mathrm{SR})_{24}(x=1.32)$ and its tetrahedral $\mathrm{M}_{4}$ $(\mathrm{M}=\mathrm{Au} / \mathrm{Ag})$ kernel surrounded by four $\mathrm{Ag}_{3}$ triangles. $\mathbf{b}$ Crystal structure of $\mathrm{Au}_{x} \mathrm{Ag}_{28-x} \mathrm{Cu}_{12}(\mathrm{SR})_{24}(x=7.56)$ and its tetrahedral $\mathrm{Au}_{4}$ kernel surrounded by four $M_{3}(M=A u / A g)$ triangles. The red arrows represent the trend of kernel collapse from "tetrahedral $\mathrm{Au}_{4}+4 * \mathrm{M}_{3}$ " to "hollow icosahedral $\mathrm{Au}_{12}$ ". c Crystal structure of $\mathrm{Au}_{12} \mathrm{Cu}_{y} \mathrm{Ag}_{32-y}(\mathrm{SR})_{30}(y=3.74)$ and its hollow icosahedral $\mathrm{Au}_{12}$ kernel. Color labels: light blue, $\mathrm{Ag}$; orange, $\mathrm{Au}$; green, $\mathrm{Cu}$; red, S. All $\mathrm{C}$ and $\mathrm{H}$ atoms are omitted for clarity.
Fig. 3d). For easily distinguishing these $\mathrm{M}_{3}$ positions, we define these $\mathrm{Au}_{3}$ positions as "stable location" (Supplementary Fig. 3c) and "unstable location" (Supplementary Fig. 3d). However, the Au doping on stable locations is simply concluded from the crystallography, and the $\mathrm{Au}$ positions may change throughout the crystallization process. From ESI-MS results (Supplementary Fig. 14), a maximum of 18-19 $\mathrm{Au}$ heteroatoms could be doped into the $\mathrm{M}_{40}$ cluster framework, $>16$ positions from the $\mathrm{M}_{4}$ kernel and $4 * \mathrm{M}_{3}$ stable locations; accordingly, there are other $\mathrm{Ag}$ positions in $\mathrm{M}_{40}$ that could be occupied by the introduced Au. X-ray absorption fine structure spectroscopy (XAFS) measurements were then performed for grasping the in-situ Audoping process (Supplementary Figs. 29 and 30 and Supplementary Tables 3-4). The XAFS results demonstrated that the introduced Au occupied the innermost $\mathrm{M}_{4}$ tetrahedron first, and then substituted the $\mathrm{Ag}$ atoms in unstable locations, different from the crystal results wherein the unstable locations were maintained as undoped Ag throughout. We further crystallized this cluster sample and the crystal data suggested the $\mathrm{Au}$ heteroatoms on stable locations (i.e., $\mathrm{Au}_{x} \mathrm{Ag}_{28}$ $\left.{ }_{x} \mathrm{Cu}_{12}(\mathrm{SR})_{24}, x=7.76\right)$, demonstrating the intracluster $\mathrm{Au}-\mathrm{Ag}$ metal exchange throughout the crystallization. In this context, we made some speculations on mass signals (Supplementary Fig. 14): the introduced $\mathrm{Au}$ heteroatoms occupied the innermost tetrahedron first, and then substituted $\mathrm{Ag}$ atoms on $\mathrm{M}_{40}-\mathrm{S} 2$ randomly; the mass signals $\mathrm{i}$ represented the dominant Au-occupation in stable locations, whereas the signals ii represented the unstable locations, resulting in two groups of signals in the 3-min mass spectrum (Supplementary Fig. 14). In the 3-min sample, the $M_{40}$ with Au-occupation in unstable locations might be the main product by referring XAFS results. Then, the $M_{40}$ clusters of signals ii would transform to $M_{44}$ clusters of signals iii, and then decomposed due to their instability. By comparison, the $\mathrm{M}_{40}$ clusters of signals i were continually doped by $\mathrm{Au}$ and transformed to $\mathrm{M}_{44}$ clusters of signals iv finally. In this context, the driving force for the transformation from $M_{40}$ to $M_{44}$ was determined as the Au-alloying at unstable locations, which rendered the $\mathrm{M}_{40}$ nanoclusters unstable molecules and triggered the kernel collapse from several small nano-building blocks to an integrated hollow icosahedron.

Significantly, the further Au-alloying induced the transformation from $\mathrm{M}_{40}(\mathrm{SR})_{24}$ to $\mathrm{M}_{44}(\mathrm{SR})_{30}$, among which process the hollow icosahedral $\mathrm{Au}_{12}$ was generated (Fig. 3b, c). Structurally, the pre-transformed $\mathrm{Au}_{x} \mathrm{Ag}_{28-x} \mathrm{Cu}_{12}(\mathrm{SR})_{24}$ possesses a "tetrahedral $\mathrm{Au}_{4}+4^{*} \mathrm{M}_{3}$ " kernel $(\mathrm{M}=\mathrm{Au} / \mathrm{Ag}$ with a high $\mathrm{Au}$ proportion). Upon the nanocluster conversion, the $\mathrm{M}_{3}$ triangles collapsed inward to the $\mathrm{Au}_{4}$ tetrahedron, and finally rearranged into the hollow icosahedral $\mathrm{Au}_{12}$ kernel in $\mathrm{Au}_{12} \mathrm{Cu}_{y} \mathrm{Ag}_{32-y}(\mathrm{SR})_{30}$ (Fig. 3c). Of note, there are 16 metal atoms in the "tetrahedral $\mathrm{M}_{4}+4^{*} \mathrm{M}_{3}$ " kernel while the icosahedral kernel only contains 12 metal atoms; in this context, a structural rearrangement occurred in this structural and kernel transformation (indeed, the "kernel +surface" configurations between $\mathrm{M}_{40}(\mathrm{SR})_{24}$ and $\mathrm{M}_{44}(\mathrm{SR})_{30}$ nanoclusters are different). However, due to the existence of several isoabsorption points in the UV-vis spectra, the structure transformation from $\mathrm{M}_{40}(\mathrm{SR})_{24}$ to $\mathrm{M}_{44}(\mathrm{SR})_{30}$ should follow an "intramolecular rearrangement" approach, but not an "intermolecular decomposition-recombination" approach. Accordingly, it is reasonable to conjecture the formation of icosahedral $\mathrm{M}_{12}$ in $\mathrm{M}_{44}(\mathrm{SR})_{30}$ as the kernel collapse from "tetrahedral $\mathrm{Au}_{4}+4^{*} \mathrm{M}_{3}$ ". Besides, all sites in the hollow icosahedron are fully occupied by $\mathrm{Au}$ (i.e., $\mathrm{Au}_{12}$ ); in vivid contrast, the non-hollow $\mathrm{M}_{1} @ \mathrm{M}_{12}$ kernels of previously alloy clusters are always partially occupied by two or more types of metals. We proposed that the complete Au occupation of the hollow icosahedron resulted from the kernel collapse in which process only the collapse of $\mathrm{Au}$ atom to $\mathrm{Au}_{4}$ was the most energetically favorable.

This avenue (i.e., kernel collapse) is of great importance since it maps out a reasonable avenue for the generation of the hollow 
icosahedral $\mathrm{M}_{12}$ kernel in metal nanoclusters. Besides, the kernel collapse might be a very common approach in constructing metallic kernels of nanoclusters and nanoparticles (not limited to the hollow icosahedron, but also compliant to other configurations such as non-hollow icosahedron, FCC/BCC kernels, etc.), because the routine growth of several large-sized nanoclusters shell-by-shell should be not that energetically favorable. We also note that the kernel collapse should not be the unique approach for the generation of hollow icosahedra (or other structures) in metal nanoclusters and nanoparticles; other approaches may also exist and are still worth mapping out.

\section{Discussion}

In summary, on the basis of the Au-alloying-induced transformation from $\mathrm{M}_{40}(\mathrm{SR})_{24}$ to $\mathrm{M}_{44}(\mathrm{SR})_{30}(\mathrm{M}=\mathrm{Au} / \mathrm{Ag} / \mathrm{Cu})$, a reasonable avenue-kernel collapse-for the generation of the hollow icosahedral $\mathrm{M}_{12}$ kernel in metal nanoclusters has been mapped out. The $\mathrm{Au}$ alloying on $\mathrm{Ag}_{28} \mathrm{Cu}_{12}(\mathrm{SR})_{24}$ produced template-maintained $\mathrm{Au}_{x} \mathrm{Ag}_{28-x} \mathrm{Cu}_{12}(\mathrm{SR})_{24}(x=1.32), \mathrm{Au}_{x} \mathrm{Ag}_{28-}$ ${ }_{x} \mathrm{Cu}_{12}(\mathrm{SR})_{24}(x=7.56)$, and template-transformed $\mathrm{Au}_{12} \mathrm{Cu}_{y} \mathrm{Ag}_{32}$ ${ }_{y}(\mathrm{SR})_{30}(y=3.74)$ step by step, accompanying with which processes the cluster kernel stepwisely evolved from "tetrahedral $\mathrm{Ag}_{4}+4^{*} \mathrm{Ag}_{3}$ " to "tetrahedral $\mathrm{Au}_{4}+4^{*} \mathrm{Ag}_{3}$ ", then to "tetrahedral $\mathrm{Au}_{4}+4^{*} \mathrm{Au}_{3}$ ", and finally to "hollow icosahedral $\mathrm{Au}_{12}$ ". The entire process was tracked by ESI-MS, and the crystal structures of the key nodes (altogether five crystal structures) have been determined. Overall, this work presents a reasonable avenue for comprehending the generation of hollow icosahedra in metal nanoclusters, and the "structure collapse" might be a very common approach for constructing kernel structures (not limited to the hollow icosahedron) in the size growth of nanoclusters and nanoparticles.

\section{Methods}

Materials. All reagents were purchased from Sigma-Aldrich and used without further purification: silver nitrate $\left(\mathrm{AgNO}_{3}, 99 \%\right.$, metal basis), tetrachloroauric (III) acid $\left(\mathrm{HAuCl}_{4} \cdot 3 \mathrm{H}_{2} \mathrm{O}, 99.99 \%\right.$ metal basis), copper(II) acetylacetonate $\left(\mathrm{Cu}\left(\mathrm{O}_{2} \mathrm{C}_{5} \mathrm{H}_{7}\right)_{2}, 99 \%\right.$, metal basis), 2,4-dichlorobenzenethiol ( $\left.\mathrm{HSPhCl}_{2}, 99 \%\right)$, sodium borohydride $\left(\mathrm{NaBH}_{4}, 97 \%\right)$, tetraphenylphosphonium bromide $\left(\left(\mathrm{PPh}_{4}\right) \mathrm{Br}\right.$, $95 \%)$, dichloromethane $\left(\mathrm{CH}_{2} \mathrm{Cl}_{2}\right.$, HPLC, Sigma-Aldrich), methanol $\left(\mathrm{CH}_{3} \mathrm{OH}\right.$, HPLC, Sigma-Aldrich), N,N-dimethylformamide (DMF, HPLC, Sigma-Aldrich), hexane $\left(\mathrm{C}_{6} \mathrm{H}_{6}\right.$, HPLC, Sigma-Aldrich), and ethyl ether $\left(\left(\mathrm{CH}_{3} \mathrm{CH}_{2}\right) \mathrm{O}\right.$, HPLC, Sigma-Aldrich).

Synthesis of $\mathbf{A u}(\mathbf{I})-\mathbf{S P h C l}$. For the $\mathrm{Au}(\mathrm{I})-\mathrm{SPhCl}_{2}$ complexes synthesis, $\mathrm{HAuCl}_{4} \cdot 3 \mathrm{H}_{2} \mathrm{O}(1 \mathrm{mmol})$ was dissolved in $5 \mathrm{~mL} \mathrm{CH}_{3} \mathrm{OH}$, and 2,4-dichlorobenzenethiol $(500 \mu \mathrm{L}, 4 \mathrm{mmol})$ was dissolved in $5 \mathrm{~mL} \mathrm{CH}_{3} \mathrm{OH}$ and added dropwise to the solution under vigorously stirring $(\sim 1200 \mathrm{rpm})$. After reacted for $15 \mathrm{~min}$, the resulting precipitate was washed several times with hexane. Then the final product was used directly.

Synthesis of $\left[\mathbf{A g}_{\mathbf{2}} \mathrm{Cu}_{\mathbf{1 2}}\left(\mathbf{S P h C l}_{\mathbf{2}}\right)_{\mathbf{2 4}}\right]^{\mathbf{4}-}$. The $\mathrm{Ag}_{28} \mathrm{Cu}_{12}\left(\mathrm{SPhCl}_{2}\right)_{24}$ was prepared by a literature method reported by the Zheng group with some modification ${ }^{57}$. Specifically, $60 \mathrm{mg}$ of $\mathrm{Cu}\left(\mathrm{O}_{2} \mathrm{C}_{5} \mathrm{H}_{7}\right)_{2}$ was dissolved in $5 \mathrm{~mL}$ of $\mathrm{CH}_{3} \mathrm{OH}$ and $15 \mathrm{~mL}$ of $\mathrm{CH}_{2} \mathrm{Cl}_{2}$, to which $60 \mathrm{mg} \mathrm{AgNO}$ (dissolved in $2 \mathrm{~mL}$ of $\mathrm{H}_{2} \mathrm{O}$ ) was added. After stirring for $20 \mathrm{~min}$, $100 \mu \mathrm{L}$ of $\mathrm{HSPCl}_{2}$ was added in, and the reaction further processed for $30 \mathrm{~min}$. Then, $30 \mathrm{mg} \mathrm{NaBH}$ (dissolved in $2 \mathrm{~mL}$ of $\mathrm{H}_{2} \mathrm{O}$ ) was added in. The reaction was allowed to proceed for $5 \mathrm{~h}$. After that, the aqueous layer was removed, and the mixture in the organic phase was rotavaporated under vacuum. Then $50 \mathrm{~mL}$ of $\mathrm{CH}_{3} \mathrm{OH}$ was used to extract the $\mathrm{Ag}_{28} \mathrm{Cu}_{12}\left(\mathrm{SPhCl}_{2}\right)_{24}$ nanocluster, to which supernatant $20 \mathrm{mg}$ of $\left(\mathrm{PPh}_{4}\right) \mathrm{Br}$ was added in. The precipitate was then washed three times by $\mathrm{CH}_{3} \mathrm{OH}$. Then the final product, i.e., $\left[\mathrm{Ag}_{28} \mathrm{Cu}_{12}\left(\mathrm{SPCl}_{2}\right)_{24}\right]^{4-}\left(\mathrm{PPh}_{4}\right)_{4}$, was used directly. The yield is $35 \%$ based on the $\mathrm{Ag}$ element (calculated from the $\mathrm{AgNO}_{3}$ ).

\footnotetext{
Syntheses of $\left[\mathrm{Au}_{x} \mathrm{Ag}_{28-x} \mathrm{Cu}_{12}\left(\mathrm{SPhCl}_{2}\right)_{24}\right]^{4-}(\mathrm{x}=1.32),\left[\mathrm{Au}_{\mathrm{x}} \mathrm{Ag}_{28-x} \mathrm{Cu}_{12}\left(\mathrm{SPhCl}_{2}\right)_{24}\right]$ ${ }^{4-}(x=7.56)$, and $\left[\mathrm{Au}_{12} \mathrm{Cu}_{y} \mathrm{Ag}_{32-y}\left(\mathrm{SPhCl}_{2}\right)_{30}\right]^{4-}$ nanoclusters. These three nanoclusters were prepared from parallel Au-alloying reactions (in the same condition but were stopped at different times). Specifically, $20 \mathrm{mg}$ of $\mathrm{Ag}_{28} \mathrm{Cu}_{12}\left(\mathrm{SPhCl}_{2}\right)_{24}$ was first dissolved in $20 \mathrm{~mL}$ of $\mathrm{CH}_{2} \mathrm{Cl}_{2}$ and then $5 \mathrm{mg}$ of $\mathrm{Au}(\mathrm{I})-\mathrm{SPhCl}_{2}$ complexes was added in. After $2 \mathrm{~min}, 100 \mathrm{~mL}$ of hexane was poured in to pause the reaction; the precipitate was
}

then dissolved in $20 \mathrm{~mL}$ of $\mathrm{CH}_{2} \mathrm{Cl}_{2}$ to yield the $\mathrm{Au}_{x} \mathrm{Ag}_{28-x} \mathrm{Cu}_{12}\left(\mathrm{SPhCl}_{2}\right)_{24}(x=1.32)$. Expanding the reaction time from $2 \mathrm{~min}$ to $3 \mathrm{~min}$ would produce the $\mathrm{Au}_{x} \mathrm{Ag}_{28-}$ ${ }_{x} \mathrm{Cu}_{12}\left(\mathrm{SPhCl}_{2}\right)_{24}(x=7.56)$. Expanding the reaction time from $2 \mathrm{~min}$ to $8 \mathrm{~min}$ would produce the $\mathrm{Au}_{12} \mathrm{Cu}_{y} \mathrm{Ag}_{32-y}\left(\mathrm{SPhCl}_{2}\right)_{30}$.

Synthesis of $\left[\mathbf{A u}_{\mathbf{1 2}} \mathbf{A g}_{\mathbf{3 2}}\left(\mathbf{S P h C l}_{\mathbf{2}}\right)_{\mathbf{3 0}}\right]^{\mathbf{4}-}$. The $\mathrm{Au}_{12} \mathrm{Ag}_{32}\left(\mathrm{SPCl}_{2}\right)_{30}$ nanocluster was prepared by a literature method reported by the Zheng group ${ }^{58}$.

Preparation of XAFS samples. In all, $10 \mathrm{mg}$ of $\mathrm{Ag}_{28} \mathrm{Cu}_{12}\left(\mathrm{SPhCl}_{2}\right)_{24}$ was dissolved in $10 \mathrm{~mL}$ of $\mathrm{CH}_{2} \mathrm{Cl}_{2}$ and then $3 \mathrm{mg}$ of $\mathrm{Au}(\mathrm{I})-\mathrm{SPhCl}_{2}$ complexes was added in. After $1 \mathrm{~min}, 200 \mathrm{~mL}$ of hexane was poured in to pause the reaction; the precipitate was then dissolved in $5 \mathrm{~mL}$ of $\mathrm{CH}_{2} \mathrm{Cl}_{2}$ to yield the $\mathrm{Au}_{x} \mathrm{Ag}_{28-x} \mathrm{Cu}_{12}\left(\mathrm{SPhCl}_{2}\right)_{24}$ (Sample 1). In total, $10 \mathrm{mg}$ of $\mathrm{Ag}_{28} \mathrm{Cu}_{12}\left(\mathrm{SPCl}_{2}\right)_{24}$ was first dissolved in $10 \mathrm{~mL}$ of $\mathrm{CH}_{2} \mathrm{Cl}_{2}$ and then $3 \mathrm{mg}$ of $\mathrm{Au}(\mathrm{I})-\mathrm{SPhCl}_{2}$ complexes was added in. After $2 \mathrm{~min}, 200 \mathrm{~mL}$ of hexane was poured in to pause the reaction; the precipitate was then dissolved in $5 \mathrm{~mL}$ of $\mathrm{CH}_{2} \mathrm{Cl}_{2}$ to yield the $\mathrm{Au}_{x} \mathrm{Ag}_{28-x} \mathrm{Cu}_{12}\left(\mathrm{SPhCl}_{2}\right)_{24}$ (Sample 2). Single crystals of XAFS Sample 2 (i.e., $\left.\mathrm{Au}_{x} \mathrm{Ag}_{28-x} \mathrm{Cu}_{12}\left(\mathrm{SPCl}_{2}\right)_{24}, x=7.76\right)$ were cultivated at room temperature by vapor diffusing the ethyl ether into the DMF solution of nanoclusters.

Crystallization of $\left[\mathrm{Ag}_{28} \mathrm{Cu}_{12}\left(\mathrm{SPhCl}_{2}\right)_{24}\right]_{1}\left(\mathrm{PPh}_{4}\right)_{4},\left[\mathrm{Au}_{\mathrm{x}} \mathrm{Ag}_{28}\right.$ $\left.{ }_{x} \mathrm{Cu}_{12}\left(\mathrm{SPhCl}_{2}\right)_{24}\right]_{1}\left(\mathrm{PPh}_{4}\right)_{4}(x=1.32),\left[\mathrm{Au}_{x} \mathrm{Ag}_{28-x} \mathrm{Cu}_{12}\left(\mathrm{SPhCl}_{2}\right)_{24}\right]_{1}\left(\mathrm{PPh}_{4}\right)_{3}$ $(x=7.56),\left[\mathrm{Au}_{x} \mathrm{Ag}_{28-x} \mathrm{Cu}_{12}\left(\mathrm{SPhCl}_{2}\right)_{24}\right]_{1}\left(\mathrm{PPh}_{4}\right)_{4}(x=7.76),\left[\mathrm{Au}_{12} \mathrm{Cu}_{y} \mathrm{Ag}_{32-}\right.$ $\left.y_{y}\left(\mathrm{SPhCl}_{2}\right)_{30}\right]^{4-}$ and $\left[\mathrm{Au}_{12} \mathrm{Ag}_{32}\left(\mathrm{SPhCl}_{2}\right)_{30}\right]_{1}\left[\mathrm{~N}\left(\mathrm{C}_{4} \mathrm{H}_{9}\right)_{4}\right]_{4}$ nanoclusters. Single crystals of these nanoclusters were cultivated at room temperature by vapor diffusing the ethyl ether into the DMF solution of them. After 21 days, black crystals were collected, and the structures of these nanoclusters were determined. The CCDC number of $\left[\mathrm{Ag}_{28} \mathrm{Cu}_{12}\left(\mathrm{SPhCl}_{2}\right)_{24}\right]_{1}\left(\mathrm{PPh}_{4}\right)_{4}$ is 2009375 ; the CCDC number of $\left[\mathrm{Au}_{x} \mathrm{Ag}_{28-x} \mathrm{Cu}_{12}\left(\mathrm{SPhCl}_{2}\right)_{24}\right]_{1}\left(\mathrm{PPh}_{4}\right)_{4}(x=1.32)$ is 2009456; the CCDC number of $\left[\mathrm{Au}_{x} \mathrm{Ag}_{28-x} \mathrm{Cu}_{12}\left(\mathrm{SPhCl}_{2}\right)_{24}\right]_{1}\left(\mathrm{PPh}_{4}\right)_{3}(x=7.56)$ is 2009457; the CCDC number of $\left[\mathrm{Au}_{x} \mathrm{Ag}_{28-x} \mathrm{Cu}_{12}\left(\mathrm{SPhCl}_{2}\right)_{24}\right]_{1}\left(\mathrm{PPh}_{4}\right)_{4}$ $(x=7.76)$ is 2083130 ; the CCDC number of $\left[\mathrm{Au}_{12} \mathrm{Cu}_{y} \mathrm{Ag}_{32-y}\left(\mathrm{SPhCl}_{2}\right)_{30}\right]^{4-}$ is 2009378; and the CCDC number of $\left[\mathrm{Au}_{12} \mathrm{Ag}_{32}\left(\mathrm{SPhCl}_{2}\right)_{30}\right]_{1}\left[\mathrm{~N}\left(\mathrm{C}_{4} \mathrm{H}_{9}\right)_{4}\right]_{4}$ is 1936551. Of note, the perfect crystal data of $\left[\mathrm{Au}_{12} \mathrm{Cu}_{y} \mathrm{Ag}_{32-y}\left(\mathrm{SPhCl}_{2}\right)_{30}\right]^{4-}$ remained unavailable despite our repeated efforts, and we only got its kernel structure (i.e., $\mathrm{Au}_{12} \mathrm{Cu}_{y} \mathrm{Ag}_{32-y} \mathrm{~S}_{30}$ ) while the peripheral $\mathrm{C}, \mathrm{H}$, and $\mathrm{Cl}$ atoms were hard to determine.

Co-crystallization between $\mathrm{M}_{\mathbf{4 0}}\left(\mathrm{SPhCl}_{2}\right)_{24}$ and $\mathbf{M}_{44}\left(\mathrm{SPhCl}_{2}\right)_{30}$ nanoclusters $\left(\left[\mathrm{Au}_{\mathbf{4}} \mathbf{A g}_{\mathbf{2 4}} \mathrm{Cu}_{\mathbf{1 2}}(\mathrm{SR})_{\mathbf{2 4}}\right]_{2}\left[\mathrm{Au}_{12} \mathrm{Cu}_{\mathbf{y}} \mathbf{A g}_{\mathbf{3 2}-\mathrm{y}}(\mathrm{SR})_{\mathbf{3 0}}\right]_{1}, \mathbf{y}=\mathbf{3 . 7 4}\right)$. In all, $20 \mathrm{mg}$ of $\mathrm{Au}_{12} \mathrm{Cu}_{y} \mathrm{Ag}_{32-y}\left(\mathrm{SPhCl}_{2}\right)_{30}$ (8-min sample in Supplementary Fig. 8) and $20 \mathrm{mg}$ of $\mathrm{Au}_{x} \mathrm{Ag}_{28-x} \mathrm{Cu}_{12}\left(\mathrm{SPhCl}_{2}\right)_{30}$ (2-min sample in Supplementary Fig. 14) were dissolved in $5 \mathrm{~mL}$ of DMF. Single crystals of the co-crystallized nanoclusters were cultivated at room temperature by vapor diffusing the ethyl ether into the DMF solution. After 21 days, black crystals were collected, and the structure of the co-crystallized nanoclusters was determined. The CCDC number of the co-crystallized $\left[\mathrm{Au}_{4} \mathrm{Ag}_{24} \mathrm{Cu}_{12}(\mathrm{SR})_{24}\right]_{2}\left[\mathrm{Au}_{12} \mathrm{Cu}_{y} \mathrm{Ag}_{32-y}(\mathrm{SR})_{30}\right]_{1}(y=3.74)$ is 2009377.

Time-dependent ESI-MS of the Au alloying process on $\mathrm{Ag}_{28} \mathrm{Cu}_{12}\left(\mathrm{SPhCl}_{2}\right)_{24}$. In total, $20 \mathrm{mg}$ of $\mathrm{Ag}_{28} \mathrm{Cu}_{12}\left(\mathrm{SPhCl}_{2}\right)_{24}$ was firstly dissolved in $20 \mathrm{~mL}$ of $\mathrm{CH}_{2} \mathrm{Cl}_{2}$ and then $5 \mathrm{mg}$ of $\mathrm{Au}(\mathrm{I})-\mathrm{SPhCl}_{2}$ complexes (powder) was added in. The ESI-MS measurement of the reaction was performed every minute.

X-ray absorption fine structure spectroscopy measurements. XAFS measurements at the Au L3-edge $(11919 \mathrm{eV})$ were performed at the beamline BL14W1 station of the Shanghai Synchrotron Radiation Facility (SSRF), China. The storage ring of the SSRF was working at an energy of $3.5 \mathrm{GeV}$ with an average electron current of $300 \mathrm{~mA}$. The hard X-ray was monochromatized with a Si (311) monochromator. XAFS data were collected in the transmission mode in the energy range from 200 below to $1000 \mathrm{eV}$ above the Au L3-edge. The acquired XAFS data were processed according to the standard procedures using the ARTEMIS module implemented in the IFEFFIT software packages.

X-ray crystallography. For the crystal date of $\mathrm{Ag}_{28} \mathrm{Cu}_{12}\left(\mathrm{SPhCl}_{2}\right)_{24}$, $\mathrm{Au}_{x} \mathrm{Ag}_{28-x} \mathrm{Cu}_{12}\left(\mathrm{SPhCl}_{2}\right)_{24}(x=1.32), \mathrm{Au}_{12} \mathrm{Cu}_{y} \mathrm{Ag}_{32-y}\left(\mathrm{SPhCl}_{2}\right)_{30}$ $\mathrm{Au}_{x} \mathrm{Ag}_{28-x} \mathrm{Cu}_{12}\left(\mathrm{SPhCl}_{2}\right)_{24}(x=7.76)$, and the co-crystallized $\left[\mathrm{Au}_{4} \mathrm{Ag}_{24} \mathrm{Cu}_{12}(\mathrm{~S}\right.$ $\left.\mathrm{R})_{24}\right]_{2}\left[\mathrm{Au}_{12} \mathrm{Cu}_{y} \mathrm{Ag}_{32-y}(\mathrm{SR})_{30}\right]_{1}(y=3.74)$ : the data collection for single-crystal $\mathrm{X}$-ray diffraction was carried out on Stoe Stadivari diffractometer under nitrogen flow, using graphite-monochromatized $\mathrm{Cu} \mathrm{Ka}$ radiation $(\lambda=1.54186 \AA)$. For the crystal date of $\mathrm{Au}_{x} \mathrm{Ag}_{28-x} \mathrm{Cu}_{12}\left(\mathrm{SPhCl}_{2}\right)_{24}(x=7.56)$, $\mathrm{Au}_{12} \mathrm{Ag}_{32}\left(\mathrm{SPCl}_{2}\right)_{30}$ : the data collection for single crystal X-ray diffraction was carried out on a Bruker Smart APEX II CCD diffractometer under liquid nitrogen flow, using graphite-monochromatized Mo Ka radiation $(\lambda=0.71069 \AA)$. Data reductions and absorption corrections were performed using the SAINT and SADABS programs, respectively ${ }^{63}$. The structure was solved by direct methods and refined with full-matrix least squares on $\mathrm{F}^{2}$ using the SHELXTL software package ${ }^{64}$. All non-hydrogen atoms were refined 
anisotropically, and all the hydrogen atoms were set in geometrically calculated positions and refined isotropically using a riding model. All crystal structures were treated with PLATON SQUEEZE, and the diffuse electron densities from these residual solvent molecules were removed ${ }^{65}$.

Characterization. The UV-vis absorption spectra of nanoclusters were recorded using an Agilent 8453 diode array spectrometer. Electrospray ionization mass spectrometry (ESI-MS) measurements were performed by MicrOTOF-QIII highresolution mass spectrometer. The sample was directly infused into the chamber at $5 \mu \mathrm{L} / \mathrm{min}$. For preparing the ESI samples, nanoclusters were dissolved in $\mathrm{CH}_{2} \mathrm{Cl}_{2}$ $(1 \mathrm{mg} / \mathrm{mL})$ and diluted $(v / v=1: 2)$ by $\mathrm{CH}_{3} \mathrm{OH}$. Energy-dispersive X-ray spectroscopy (EDS) mapping of nanoclusters were characterized by SEM (Quanta $400 \mathrm{~F}$ ). $\mathrm{X}$-ray photoelectron spectroscopy (XPS) measurements were performed on a Thermo ESCALAB 250 configured with a monochromatized $\mathrm{Al} \mathrm{K} \alpha(1486.8 \mathrm{eV})$ $150 \mathrm{~W}$ X-ray source, $0.5 \mathrm{~mm}$ circular spot size, flood gun to counter charging effects, and analysis chamber base pressure lower than $1 \times 10^{-9} \mathrm{mbar}$.

\section{Data availability}

The X-ray crystallographic coordinates for structures reported in this work have been deposited at the Cambridge Crystallographic Data Center (CCDC), under deposition numbers CCDC-2009375, 2009456, 2009457, 2009377, 2009378, and 2083130. These data can be obtained free of charge from the Cambridge Crystallographic Data Centre via www.ccdc.cam.ac.uk/data_request/cif, which has been mentioned in the article.

Received: 7 June 2021; Accepted: 29 September 2021;

Published online: 26 October 2021

\section{References}

1. Chakraborty, I. \& Pradeep, T. Atomically precise clusters of noble metals: emerging link between atoms and nanoparticles. Chem. Rev. 117, 8208-8271 (2017).

2. Hossain, S. et al. Alloy clusters: precise synthesis and mixing effects. Acc. Chem. Res. 51, 3114-3124 (2018)

3. Sharma, S. et al. Structurally precise dichalcogenolate-protected copper and silver superatomic nanoclusters and their alloys. Acc. Chem. Res. 51, 2475-2483 (2018).

4. Konishi, K., Iwasaki, M. \& Shichibu, Y. Phosphine-ligated gold clusters with core+exo geometries: unique properties and interactions at the ligand-cluster interface. Acc. Chem. Res. 51, 3125-3133 (2018).

5. Bhattarai, B. et al. Chemistry and structure of silver molecular nanoparticles. Acc. Chem. Res. 51, 3104-3113 (2018).

6. Chen, T. et al. Electrospray ionization mass spectrometry: a powerful platform for noble-metal nanocluster analysis. Angew. Chem. Int. Ed. 58, 11967-11977 (2019).

7. Yang, D. et al. Controllable conversion of $\mathrm{CO}_{2}$ on non-metallic gold clusters. Angew. Chem. Int. Ed. 59, 1919-1924 (2020).

8. Guan, Z.-J. et al. Isomerization in alkynyl-protected gold nanoclusters. J. Am. Chem. Soc. 142, 2995-3001 (2020).

9. Kenzler, S., Schrenk, C. \& Schnepf, A. $\mathrm{Au}_{108} \mathrm{~S}_{24}\left(\mathrm{PPh}_{3}\right)_{16}$ : a highly symmetric nanoscale gold cluster confirms the general concept of metalloid clusters. Angew. Chem. Int. Ed. 56, 393-396 (2017)

10. Yuan, S.-F. et al. A ligand-protected golden fullerene: the dipyridylamido Au328+ nanocluster. Angew. Chem. Int. Ed. 58, 5906-5909 (2019).

11. Kenzler, S. et al. Synthesis and characterization of three multi-shell metalloid gold clusters $\mathrm{Au}_{32}\left(\mathrm{R}_{3} \mathrm{P}\right)_{12} \mathrm{Cl}_{8}$. Angew. Chem. Int. Ed. 58, 5902-5905 (2019).

12. Narouz, M. R. et al. N-heterocyclic carbene-functionalized magic-number gold nanoclusters. Nat. Chem. 11, 419-425 (2019).

13. Tasaka, Y. et al. Electron binding in a superatom with a repulsive coulomb barrier: the case of $\left[\mathrm{Ag}_{44}\left(\mathrm{SC}_{6} \mathrm{H}_{3} \mathrm{~F}_{2}\right)_{30}\right]^{4-}$ in the gas phase. J. Phys. Chem. Lett. 11, 3069-3074 (2020).

14. Huard, D. J. E. et al. Atomic structure of a fluorescent $\mathrm{Ag}_{8}$ cluster templated by a multistranded DNA scaffold. J. Am. Chem. Soc. 141, 11465-11470 (2018).

15. Wang, Z. et al. A hierarchically assembled 88-nuclei silver-thiacalix[4]arene nanocluster. Nat. Commun. 11, 308 (2020)

16. Zhuang, S. et al. Hard-sphere random close-packed $\mathrm{Au}_{47} \mathrm{Cd}_{2}(\mathrm{TBBT})_{31}$ nanoclusters with a faradaic efficiency of up to $96 \%$ for electrocatalytic $\mathrm{CO}_{2}$ reduction to CO. Angew. Chem. Int. Ed. 59, 3073-3077 (2020).

17. $\mathrm{Qu}, \mathrm{M}$. et al. Observation of non-FCC copper in alkynyl-protected Cu53 nanoclusters. Angew. Chem. Int. Ed. 59, 6507-6512 (2020).

18. Sun, C. et al. Atomically precise, thiolated copper-hydride nanoclusters as single-site hydrogenation catalysts for ketones in mild conditions. ACS Nano 13, 5975-5986 (2019).

19. Baghdasaryan, A. et al. Thiolato protected copper sulfide cluster with the tentative composition $\mathrm{Cu}_{74} \mathrm{~S}_{15}(2-\mathrm{PET})_{45}$. Inorg. Chem. 59, 2200-2208 (2020).
20. Sakthivel, N. A. et al. Crystal structure of faradaurate-279: $A_{279}(S P h-t B u)_{84}$ plasmonic nanocrystal molecules. J. Am. Chem. Soc. 139, 15450-15459 (2017)

21. Hosier, C. A. \& Ackerson, C. J. Regiochemistry of thiolate for selenolate ligand exchange on gold clusters. J. Am. Chem. Soc. 141, 309-314 (2019).

22. Han, X.-S. et al. Structure determination of alkynyl-protected gold nanocluster $\mathrm{Au}_{22}\left({ }^{t} \mathrm{BuC} \equiv \mathrm{C}\right)_{18}$ and its thermochromic luminescence. Angew. Chem. Int. Ed. 59, 2309-2312 (2020)

23. Cook, A. W. \& Hayton, T. W. Case studies in nanocluster synthesis and characterization: challenges and opportunities. Acc. Chem. Res. 51, 2456-2464 (2018).

24. Takano, S., Ito, S. \& Tsukuda, T. Efficient and selective conversion of phosphine-protected $\left(\mathrm{MAu}_{8}\right)^{2+}(\mathrm{M}=\mathrm{Pd}, \mathrm{Pt})$ superatoms to thiolate-protected $\left(\mathrm{MAu}_{12}\right)^{6+}$ or alkynyl-protected $\left(\mathrm{MAu}_{12}\right)^{4+}$ superatoms via hydride doping. $J$. Am. Chem. Soc. 141, 15994-16002 (2019).

25. Fei, W. et al. Metal doping of $\mathrm{Au}_{25}(\mathrm{SR})_{18}{ }^{-}$clusters: insights and hindsights. $J$. Am. Chem. Soc. 141, 16033-16045 (2019).

26. Alhilaly, M. J. et al. Assembly of atomically precise silver nanoclusters into nanocluster-based frameworks. J. Am. Chem. Soc. 141, 9585-9592 (2019).

27. Huang, R.-W. et al. $\left[\mathrm{Cu}_{81}(\mathrm{PhS})_{46}\left({ }^{t} \mathrm{BuNH}_{2}\right)_{10}(\mathrm{H})_{32}\right]^{3+}$ reveals the coexistence of large planar cores and hemispherical shells in high-nuclearity copper nanoclusters. J. Am. Chem. Soc. 142, 8696-8705 (2020).

28. Nieto-Ortega, B. \& Bürgi, T. Vibrational properties of thiolate-protected gold nanoclusters. Acc. Chem. Res. 51, 2811-2819 (2018).

29. Zhu, Y. et al. Enantioseparation of $\mathrm{Au}_{20}\left(\mathrm{PPh}_{3}\right)_{4} \mathrm{Cl}_{4}$ Clusters with Intrinsically Chiral Cores. Angew. Chem. Int. Ed. 57, 9059-9063 (2018).

30. Sugiuchi, M., Shichibu, Y. \& Konishi, K. An inherently chiral $A_{2}{ }_{24}$ framework with double-helical hexagold strands. Angew. Chem. Int. Ed. 57, 7855-7859 (2018).

31. Lu, J. et al. Giant emission enhancement of solid-state gold nanoclusters by surface engineering. Angew. Chem. Int. Ed. 59, 8270-8276 (2020).

32. Soldan, G. et al. Gold doping of silver nanoclusters: a 26-fold enhancement in the luminescence quantum yield. Angew. Chem. Int. Ed. 55, 5749-5753 (2016).

33. Weerawardene, K. L. D. M. et al. Luminescence and electron dynamics in atomically precise nanoclusters with eight superatomic electrons. J. Am. Chem. Soc. 141, 18715-18726 (2019).

34. Yan, J., Teo, B. K. \& Zheng, N. Surface chemistry of atomically precise coinage-metal nanoclusters: from structural control to surface reactivity and catalysis. Acc. Chem. Res. 51, 3084-3093 (2018).

35. Lee, $\mathrm{S}$. et al. $\left[\mathrm{Cu}_{32}(\mathrm{PET})_{24} \mathrm{H}_{8} \mathrm{Cl}_{2}\right]\left(\mathrm{PPh}_{4}\right)_{2}$ : a copper hydride nanocluster with a bisquare antiprismatic core. J. Am. Chem. Soc. 142, 13974-13981 (2020).

36. Agrachev, M. et al. Nuclear and electron magnetic resonance spectroscopies of atomically precise gold nanoclusters. Acc. Chem. Res. 52, 44-52 (2018).

37. Shen, H. et al. Highly robust but surface-active: an N-heterocyclic carbenestabilized $\mathrm{Au}_{25}$ nanocluster. Angew. Chem. Int. Ed. 58, 17731-17735 (2019).

38. Kwak, K. \& Lee, D. Electrochemistry of atomically precise metal nanoclusters Acc. Chem. Res. 52, 12-22 (2018).

39. Sakthivel, N. A. \& Dass, A. Aromatic thiolate-protected series of gold nanomolecules and a contrary structural trend in size evolution. Acc. Chem Res. 51, 1774-1783 (2018).

40. Kang, X. \& Zhu, M. Intra-cluster growth meets inter-cluster assembly: the molecular and supramolecular chemistry of atomically precise nanoclusters. Coord. Chem. Rev. 394, 1-38 (2019).

41. Weerawardene, K. L. D. M., Häkkinen, H. \& Aikens, C. M. Connections between theory and experiment for gold and silver nanoclusters. Annu. Rev. Phys. Chem. 69, 205-229 (2018).

42. Tang, Q. et al. Insights into interfaces, stability, electronic properties, and catalytic activities of atomically precise metal nanoclusters from first principles. Acc. Chem. Res. 51, 2793-2802 (2018).

43. Cirri, A. et al. Systematically tuning the electronic structure of gold nanoclusters through ligand derivatization. Angew. Chem. Int. Ed. $\mathbf{5 8}$ 13818-13822 (2019).

44. Yonesato, K. et al. Controlled assembly synthesis of atomically precise ultrastable silver nanoclusters with polyoxometalates. J. Am. Chem. Soc. 141, 19550-19554 (2019)

45. Huang, R.-W. et al. Hypersensitive dual-function luminescence switching of a silver-chalcogenolate cluster-based metal-organic framework. Nat. Chem. 9, 689-697 (2017)

46. Wang, Q.-Y. et al. $o$-Carborane-based and atomically precise metal clusters as hypergolic materials. J. Am. Chem. Soc. 142, 12010-12014 (2020).

47. Zhu, M. et al. Correlating the crystal structure of a thiol-protected $\mathrm{Au}_{25}$ cluster and optical properties. J. Am. Chem. Soc. 130, 5883-5885 (2008).

48. Joshi, C. P. et al. $\left[\mathrm{Ag}_{25}(\mathrm{SR})_{18}\right]^{-}$: the "golden" silver nanoparticle. J. Am. Chem. Soc. 137, 11578-11581 (2015).

49. Nguyen, T.-A. D. et al. A $\mathrm{Cu}_{25}$ nanocluster with partial $\mathrm{Cu}(0)$ character. J. Am Chem. Soc. 137, 13319-13324 (2015).

50. Conn, B. E. et al. Confirmation of a de novo structure prediction for an atomically precise monolayer-coated silver nanoparticle. Sci. Adv. 2, e1601609 (2016) 
51. Sun, Q. et al. Synthesis, structures, and photoluminescence of elongated facecentered-cubic $\mathrm{Ag}_{14}$ clusters containing lipoic acid and its amide analogue. Inorg. Chem. 59, 8836-8845 (2020).

52. Desireddy, A. et al. Ultrastable silver nanoparticles. Nature 501, 399-402 (2013).

53. Yang, H. et al. Structural evolution of atomically precise thiolated bimetallic $\left[\mathrm{Au}_{12+\mathrm{n}} \mathrm{Cu}_{32}(\mathrm{SR})_{30+\mathrm{n}}\right]^{4-}(\mathrm{n}=0,2,4,6)$ nanoclusters. J. Am. Chem. Soc. 136, 7197-7200 (2014).

54. Du, W. et al. $\mathrm{Ag}_{50}(\mathrm{Dppm})_{6}(\mathrm{SR})_{30}$ and its homologue $\mathrm{Au}_{x} \mathrm{Ag}_{50-x}(\mathrm{Dppm})_{6}(\mathrm{SR})_{30}$ alloy nanocluster: seeded growth, structure determination, and differences in properties. J. Am. Chem. Soc. 139, 1618-1624 (2017).

55. Yan, N. et al. Unraveling the long-pursued $\mathrm{Au}_{144}$ structure by $\mathrm{X}$-ray crystallography. Sci. Adv. 4, eaat7259 (2018).

56. Barik, S. K. et al. Polyhydrido copper nanoclusters with a hollow icosahedral core: $\left[\mathrm{Cu}_{30} \mathrm{H}_{18}\left\{\mathrm{E}_{2} \mathrm{P}(\mathrm{OR})_{2}\right\}_{12}\right](\mathrm{E}=\mathrm{S}$ or $\mathrm{Se} ; \mathrm{R}=n \mathrm{Pr}, i \mathrm{Pr}$ or $i \mathrm{Bu})$. Chem. Eur. J. 26, 10471-10479 (2020).

57. Yan, J. et al. Asymmetric synthesis of chiral bimetallic $\left[\mathrm{Ag}_{28} \mathrm{Cu}_{12}(\mathrm{SR})_{24}\right]^{4-}$ nanoclusters via ion pairing. J. Am. Chem. Soc. 138, 12751-12754 (2016)

58. Yang, $\mathrm{H}$. et al. All-thiol-stabilized $\mathrm{Ag}_{44}$ and $\mathrm{Au}_{12} \mathrm{Ag}_{32}$ nanoparticles with single-crystal structures. Nat. Commun. 4, 2422 (2013).

59. He, L. et al. Alternative array stacking of $\mathrm{Ag}_{26} \mathrm{Au}$ and $\mathrm{Ag}_{24} \mathrm{Au}$ nanoclusters Angew. Chem. Int. Ed. 58, 9897-9901 (2019).

60. Bodiuzzaman, M. et al. Camouflaging structural diversity: co-crystallization of two different nanoparticles having different cores but the same shell. Angew. Chem. Int. Ed. 58, 189-194 (2019).

61. Liu, J.-Y. et al. Different silver nanoparticles in one crystal: $\mathrm{Ag}_{210}(\mathrm{iPrPhS})_{71}\left(\mathrm{Ph}_{3} \mathrm{P}\right)_{5} \mathrm{Cl}$ and $\mathrm{Ag}_{211}(\mathrm{iPrPhS})_{71}\left(\mathrm{Ph}_{3} \mathrm{P}\right)_{6} \mathrm{Cl}$. Angew. Chem. Int. Ed. 58, 195-199 (2019).

62. Yan, J. et al. Co-crystallization of atomically precise metal nanoparticles driven by magic atomic and electronic shells. Nat. Commun. 9, 3357 (2018).

63. APEX2 Ver.2014.11-0, SAINT Ver.8.34A, SADABS Ver.2014/15, Bruker AXS, Inc., Madison, Wisconsin, USA, 2014.

64. Sheldrick, G. M. A short history of SHELX. Acta Crystallogr. A 64, 112-122 (2008).

65. Sheldrick, G. M. Crystal structure refinement with SHELXL. Acta Crystallogr. Sect. C Struct. Chem. 71, 3-8 (2015).

\section{Acknowledgements}

We acknowledge the financial support by NSFC (U1532141, 21631001, and 21871001), the Ministry of Education, the Education Department of Anhui University.

\section{Author contributions}

X.K. and X.W. carried out experiments, analyzed the data and wrote the manuscript. X.L., Si.W. and T.Y. assisted the X-ray absorption fine structure spectroscopy analysis and completed the manuscript. Sh.W. and M.Z. designed the project, analyzed the data, and revised the manuscript.

\section{Competing interests}

The authors declare no competing interests.

\section{Additional information}

Supplementary information The online version contains supplementary material available at https://doi.org/10.1038/s41467-021-26528-w.

Correspondence and requests for materials should be addressed to Tao Yao, Shuxin Wang or Manzhou Zhu.

Peer review information Nature Communications thanks the anonymous reviewer(s) for their contribution to the peer review of this work.

Reprints and permission information is available at http://www.nature.com/reprints

Publisher's note Springer Nature remains neutral with regard to jurisdictional claims in published maps and institutional affiliations.

cc) (i) Open Access This article is licensed under a Creative Commons Attribution 4.0 International License, which permits use, sharing, adaptation, distribution and reproduction in any medium or format, as long as you give appropriate credit to the original author(s) and the source, provide a link to the Creative Commons license, and indicate if changes were made. The images or other third party material in this article are included in the article's Creative Commons license, unless indicated otherwise in a credit line to the material. If material is not included in the article's Creative Commons license and your intended use is not permitted by statutory regulation or exceeds the permitted use, you will need to obtain permission directly from the copyright holder. To view a copy of this license, visit http://creativecommons.org/ licenses/by/4.0/.

(C) The Author(s) 2021 